\title{
Sulfate Minerals: A Problem for the Detection of Organic Compounds on Mars?
}

\author{
James M.T. Lewis, Jonathan S. Watson, Jens Najorka, ${ }^{2}$ Duy Luong, and Mark A. Sephton ${ }^{1}$
}

\begin{abstract}
The search for in situ organic matter on Mars involves encounters with minerals and requires an understanding of their influence on lander and rover experiments. Inorganic host materials can be helpful by aiding the preservation of organic compounds or unhelpful by causing the destruction of organic matter during thermal extraction steps. Perchlorates are recognized as confounding minerals for thermal degradation studies. On heating, perchlorates can decompose to produce oxygen, which then oxidizes organic matter. Other common minerals on Mars, such as sulfates, may also produce oxygen upon thermal decay, presenting an additional complication. Different sulfate species decompose within a large range of temperatures. We performed a series of experiments on a sample containing the ferric sulfate jarosite. The sulfate ions within jarosite break down from $500^{\circ} \mathrm{C}$. Carbon dioxide detected during heating of the sample was attributed to oxidation of organic matter. A laboratory standard of ferric sulfate hydrate released sulfur dioxide from $550^{\circ} \mathrm{C}$, and an oxygen peak was detected in the products. Calcium sulfate did not decompose below $1000^{\circ} \mathrm{C}$. Oxygen released from sulfate minerals may have already affected organic compound detection during in situ thermal experiments on Mars missions. A combination of preliminary mineralogical analyses and suitably selected pyrolysis temperatures may increase future success in the search for past or present life on Mars. Key Words: Mars-Life detectionGeochemistry-Organic matter-Jarosite. Astrobiology 15, 247-258.
\end{abstract}

\section{Introduction}

$\mathbf{O}$ RGANiC MATTER DETECTION missions sent to Mars, the Viking landers and Mars Science Laboratory (MSL), have so far offered no conclusive evidence of organic matter preserved on the planet's surface. The failure to detect organic matter in situ is paradoxical when it is considered that comets, meteorites, and interplanetary dust particles have been contributing organic compounds to the Red Planet throughout its history (Atreya et al., 2007). In addition, organic carbon phases have been detected in martian meteorites (Sephton et al., 2002; Steele et al., 2012) and martian volcanoes; life and serpentinization could also have produced organic compounds in the past and may still do so today (Atreya et al., 2007). Organic matter is therefore either accumulating at levels below detection limits, being destroyed by martian processes (Benner et al., 2000; ten Kate et al., 2005), or its presence is obscured through mission sample processing and analytical procedures.

Thermal extraction is a common in situ analysis approach (Mahaffy, 2008). However, minerals are known to influence the composition of thermal extracts (Saiz-Jiminez, 1994; Faure et al., 2006). For example, any mineral species that decomposes to give oxygen on heating may oxidize organic matter present in the sample of interest. A mineral class that has received a great deal of recent attention is the perchlorates, which are salts containing chlorine and oxygen that thermally decompose to give molecular oxygen on heating (Devlin and Herley, 1986). The Phoenix lander detected perchlorates in northern martian soils with the Microscopy, Electrochemistry, and Conductivity Analyzer (MECA) instrument (Chevrier et al., 2009; Hecht et al., 2009;

\footnotetext{
${ }^{1}$ Impacts and Astromaterials Research Centre, Department of Earth Science and Engineering, Imperial College London, London, United Kingdom.

${ }^{2}$ Impacts and Astromaterials Research Centre, Department of Mineralogy, Natural History Museum, London, United Kingdom.

(C) The Author(s) 2015; Published by Mary Ann Liebert, Inc. This Open Access article is distributed under the terms of the Creative Commons License (http://creativecommons.org/licenses/by/4.0), which permits unrestricted use, distribution, and reproduction in any medium, provided the original work is properly credited.
} 
Kounaves et al., 2010, 2014b). Perchlorate species predominantly decompose at $\leq 600^{\circ} \mathrm{C}$ (Shimokawabe et al., 1977), so their presence on Mars is further implied by Phoenix Thermal Evolved Gas Analyzer (TEGA) results, which show the evolution of oxygen in the $300-600^{\circ} \mathrm{C}$ range (Hecht et al., 2009). A corresponding release of carbon dioxide detected between $200^{\circ} \mathrm{C}$ and $600^{\circ} \mathrm{C}$ was tentatively interpreted as resulting from the combustion of organic matter facilitated by perchlorate-sourced oxygen, though no intact organic matter was detected (Ming et al., 2009). Similar interpretations have recently been applied to historical Viking pyrolysis data (Navarro-González et al., 2010). Perchlorates may form on Mars by gas phase oxidation and are probably widespread in the arid martian soils (Catling et al., 2010). In addition, perchlorate brines may be stable for brief periods of time at the Phoenix landing site (Chevrier et al., 2009). Perchlorates are a possible cause of the detection of chlorinated hydrocarbons and oxygen by the Sample Analysis at Mars (SAM) instrument on MSL (Glavin et al., 2013). The martian meteorite EETA79001 was found to contain 0.6 \pm 0.1 ppm perchlorate (Kounaves et al., 2014a).

A relatively neglected class of mineral that can decompose to produce atomic oxygen during heating is the sulfates (Holt and Engelkemeir, 1970). The sulfate ion decomposes to sulfur trioxide and then, at higher temperatures, sulfur dioxide and atomic oxygen (Bailey and Smith, 1972). Sulfur trioxide can also combine with water to form sulfuric acid (Wong et al., 2003). The presence of sulfates in mixtures introduced to pyrolysis chambers could therefore pose a similar problem to that observed for perchlorates. If the sulfate is hydrated, then the potential generation of sulfuric acid is an additional complication. Thermogravimetric studies show that most sulfates decompose at temperatures greater than $600^{\circ} \mathrm{C}$ (Table 1); however, iron and aluminum sulfates begin to decompose at temperatures similar to those used for the analysis of macromolecular organic material in pyrolysis studies ( $\mathrm{Mu}$ and Perlmutter, 1981; Sephton and Gilmour, 2001; Sephton et al., 2004, 2013; NavarroGonzález et al., 2006; Sephton, 2012).

Jarosite minerals are members of the alunite supergroup [minerals with the general formula $\mathrm{AB}_{3}\left(\mathrm{TO}_{4}\right)_{2}(\mathrm{OH})_{6}$ ]. In jarosite, the general formula is characterized by having $\mathrm{Fe}^{3+}$ in the $\mathrm{B}$ site and sulfur occupying the $\mathrm{T}$ site (Basciano and Peterson, 2008). On Earth, a natural solid solution exists in the A site of potassium, sodium, and hydronium ions (Brophy and Sheridan, 1965). The A site can also be occupied by ammonium, lead, or silver ions (Drouet and Navrotsky, 2003). It is well known that variation of the cation species in the $\mathrm{A}$ and $\mathrm{B}$ sites influences the decomposition temperature of the jarosite structure and that other sulfate species also have highly variable decomposition temperatures. Hydronium jarosite will undergo complete decomposition from $619^{\circ} \mathrm{C}$ when intermediate ferric sulfate breaks down to give iron oxide and sulfur dioxide [sulfuric acid is also produced as a decomposition intermediate and breaks down to give sulfur dioxide at $557^{\circ} \mathrm{C}$ (Table 1)] (Frost et al., 2006a). Sulfur trioxide is an intermediate in sulfate decomposition, and it breaks down to give atomic oxygen and further sulfur dioxide (Bailey and Smith, 1972). With other forms of jarosite, the iron in the B site of the general formula will still form a ferric sulfate intermediate, which decomposes at temperatures that are problematic for organic molecule de-
Table 1. Temperature at Which the Sulfate Ion Begins to Decompose to Give Sulfur DiOXIDE DURING THERMAL DECOMPOSITION of Different Sulfate Species

\begin{tabular}{|c|c|c|c|}
\hline Mineral & Formula & $\begin{array}{c}\mathrm{T} \text { at which } \\
\text { sulfate } \\
\text { decomposition } \\
\text { begins }\left({ }^{\circ} \mathrm{C}\right)\end{array}$ & $\begin{array}{c}\text { Decomposition } \\
\text { atmosphere }\end{array}$ \\
\hline Jarosite & $\mathrm{KFe}_{3}(\mathrm{OH})_{6}\left(\mathrm{SO}_{4}\right)_{2}$ & $501^{\mathrm{a}}$ & Nitrogen \\
\hline Natrojarosite & $\mathrm{NaFe}_{3}(\mathrm{OH})_{6}\left(\mathrm{SO}_{4}\right)_{2}$ & $555^{\mathrm{a}}$ & Nitrogen \\
\hline $\begin{array}{l}\text { Hydronium } \\
\text { jarosite }\end{array}$ & $\begin{array}{l}\mathrm{H}_{3} \mathrm{OFe}_{3}(\mathrm{OH})_{6} \\
\quad\left(\mathrm{SO}_{4}\right)_{2}\end{array}$ & $557^{\mathrm{b}}$ & Nitrogen \\
\hline $\begin{array}{l}\text { Ammonium } \\
\text { jarosite }\end{array}$ & $\begin{array}{l}\mathrm{NH}_{4} \mathrm{Fe}_{3}(\mathrm{OH})_{6} \\
\quad\left(\mathrm{SO}_{4}\right)_{2}\end{array}$ & $510^{\mathrm{c}}$ & Nitrogen \\
\hline Plumbojarosite & $\begin{array}{l}\mathrm{Pb}_{0.5} \mathrm{Fe}_{3}(\mathrm{OH})_{6} \\
\quad\left(\mathrm{SO}_{4}\right)_{2}\end{array}$ & $531^{\mathrm{a}}$ & Nitrogen \\
\hline Argentojarosite & $\mathrm{AgFe}_{3}(\mathrm{OH})_{6}\left(\mathrm{SO}_{4}\right)_{2}$ & $548^{\mathrm{d}}$ & Nitrogen \\
\hline Alunite & $\mathrm{KAl}_{3}(\mathrm{OH})_{6}\left(\mathrm{SO}_{4}\right)_{2}$ & $610^{\mathrm{e}}$ & Air \\
\hline Natroalunite & $\mathrm{NaAl}_{3}(\mathrm{OH})_{6}\left(\mathrm{SO}_{4}\right)_{2}$ & $590^{\mathrm{e}}$ & Air \\
\hline $\begin{array}{l}\text { Hydronium } \\
\text { alunite }\end{array}$ & $\begin{array}{l}\mathrm{H}_{3} \mathrm{OAl}_{3}(\mathrm{OH})_{6} \\
\quad\left(\mathrm{SO}_{4}\right)_{2}\end{array}$ & $680^{\mathrm{e}}$ & Air \\
\hline $\begin{array}{l}\text { Ammonium } \\
\text { alunite }\end{array}$ & $\begin{array}{l}\mathrm{NH}_{4} \mathrm{Al}_{3}(\mathrm{OH})_{6} \\
\quad\left(\mathrm{SO}_{4}\right)_{2}\end{array}$ & $660^{\mathrm{e}}$ & Air \\
\hline Ferric sulfate & $\mathrm{Fe}_{2}\left(\mathrm{SO}_{4}\right)_{3}$ & $494^{\mathrm{f}}$ & Nitrogen \\
\hline $\begin{array}{l}\text { Aluminum } \\
\text { sulfate }\end{array}$ & $\mathrm{Al}_{2}\left(\mathrm{SO}_{4}\right)_{3}$ & $580^{f}$ & Nitrogen \\
\hline Lead sulfate & $\mathrm{PbSO}_{4}$ & $759^{\mathrm{a}}$ & Nitrogen \\
\hline $\begin{array}{l}\text { Magnesium } \\
\text { sulfate }\end{array}$ & $\mathrm{MgSO}_{4}$ & $780^{f}$ & Nitrogen \\
\hline Sodium sulfate & $\mathrm{Na}_{2} \mathrm{SO}_{4}$ & $1100^{\mathrm{g}}$ & Nitrogen \\
\hline Calcium sulfate & $\mathrm{CaSO}_{4}$ & $1200^{\mathrm{h}}$ & Nitrogen \\
\hline
\end{tabular}

${ }^{\mathrm{a}}$ Frost et al. (2005a).

${ }^{\mathrm{b}}$ Frost et al. (2006a).

${ }^{c}$ Frost et al. (2006b).

${ }^{\mathrm{d}}$ Frost et al. (2005b).

${ }^{\mathrm{e}}$ Rudolph et al. (2003).

${ }^{\mathrm{f}} \mathrm{Mu}$ and Perlmutter (1981).

${ }^{\mathrm{g}}$ Samadhi et al. (2001).

${ }^{\mathrm{h}}$ West and Sutton (1953).

tection, but the A site cation will form a more stable sulfate intermediate, which does not decompose until higher temperatures (Frost et al., 2005a). Additional metal oxides, that are unrelated to the breakdown of sulfate intermediates, form during jarosite decomposition; the oxygen is sourced from the hydroxyl groups within jarosite, so these metal oxides do not act as a sink for oxygen released during the breakdown of sulfate ions within jarosite (Frost et al., 2005a).

Jarosite is a common mineral in acidic, sulfur-rich environments (Baron and Palmer, 1996). Sulfates, including jarosite, are common on Mars and are interpreted as evidence of surface and near-surface waters present at the time of their formation (Ehlmann et al., 2009). Jarosite can form by the aqueous oxidation of pyrite deposits in a saline, low $\mathrm{pH}$, low water-to-rock-ratio environment (Zolotov and Shock, 2005). Such an environment is thought to have existed in the late Noachian and Hesperian when outgassing from volcanoes released abundant sulfur and water into the martian atmosphere (Bibring et al., 2006). Noachian and Hesperian terrains are well preserved and widespread on Mars (Michalski et al., 2013). Jarosite is preserved for geological timescales only in extremely arid conditions, and the persistence of jarosite on Mars is testament to the planet's extreme surface aridity in post-Hesperian times (Elwood Madden et al., 2004). 
Sulfates are not just restricted to ancient terrains; the well-mixed dust that covers most surfaces on Mars has high concentrations of sulfates, at an average concentration of $5.82 \mathrm{wt} \%$ (Gellert et al., 2004). Magnesium sulfate is a common cementing agent in the upper few centimeters of martian soil, making up approximately $10 \mathrm{wt} \%$ (Vaniman et al., 2004). In situ analyses by landers and rovers support the assertion of widespread sulfates on Mars. Sulfur was detected in martian soils by the Viking landers at concentrations of $8-15 \%$, with magnesium and sodium sulfates being inferred as the most common mineral phases present (Clark and Van Hart, 1981). At the Pathfinder landing site, the Sojourner rover Alpha Proton X-ray Spectrometer (APXS) detected soils that contained a mean value of $6.79 \%$ sulfur (Wanke et al., 2001). The Opportunity Rover identified the ferric sulfate species jarosite and possibly gypsum at its Meridiani Planum landing site (Klingelhöfer et al., 2004), and jarosite was present in rocks of the Burns Formation at an abundance of $29 \%$ of iron species, the other species being hematite, olivine, pyroxene, and magnetite (Morris et al., 2006). While studying Gusev Crater, the Spirit Rover became embedded in sand in which ferric sulfates were a major phase (Arvidson et al., 2010). Sulfur dioxide peaks seen in MSL SAM results from the Rocknest site in Gale Crater were variable but evolved in the form of two main peaks between $450^{\circ} \mathrm{C}$ and $800^{\circ} \mathrm{C}$, and were described as consistent with the decomposition of iron sulfates (Leshin et al., 2013). However, analyses at both Rocknest and the Yellowknife Bay study site by the Chemistry and Mineralogy (CheMin) instrument of MSL found only calcium sulfates, suggesting that if iron sulfate is present it exists at levels below detection limits at these locations (Bish et al., 2013; Vaniman et al., 2014). Oxidized sulfur species are widespread in martian meteorites, with calcium and magnesium sulfates being the most common forms (Burgess et al., 1989; Gooding, 1992). Mars analog sites on Earth, such as Río Tinto and Panoche Valley, are notably sulfate-rich (Navarro-González et al., 2006).

In this paper, we examine sulfate minerals that are known to exist on Mars, focusing on jarosite, and assess their influence on organic matter detection by thermal extraction methods. The widespread and abundant nature of sulfates suggests that any effects will be almost unavoidable for in situ Mars analyses. We also compare the behavior of these sulfates with other common Mars-relevant mineral phases. Our data provide guidance for both interpreting existing data from Mars but also for directing the future operation of thermal extraction units by suggesting routes to mitigate any negative effects of sulfate decomposition on organic detection.

\section{Materials and Methods}

\subsection{Samples}

A number of Mars-relevant sulfates and other mineral types were obtained for this study. A natural jarosite clay was collected from Brownsea Island, Dorset, UK. On the southern coast of the island, subhorizontal beds of the Branksome Sand and Parkstone Clay are well exposed in the short cliffs. The Parkstone Clay unit is rich in lignite and contains pyrite. The iron sulfide oxidizes to jarosite on rock surfaces, which then further oxidizes to iron oxide at the base of the cliffs. Jarosite-enriched layers were removed from the cliff face by hammer or by hand.
A natural jarosite clay sample, rather than a pure synthetic standard, was used for this work for two reasons. Jarosite analyzed in situ on Mars will likely be present as a small percentage of a well-mixed sample (Morris et al., 2006). Secondly, the jarosite structure can undergo multiple substitutions (Basciano and Peterson, 2008). As cations exert a significant influence on decomposition temperature (Table 1), a natural jarosite clay was chosen so that the decomposition was representative of a natural cation ratio rather than a synthetic sample, which may be unnaturally enriched in a particular cation. In preparation for analysis and the main experimental work, a whole rock sample of the jarosite clay was crushed in a Tema mill.

For comparison with, and deconvolution of, the signals in the natural jarosite clay, a number of individual minerals were obtained. Laboratory standards of ferric sulfate hydrate, calcium carbonate, goethite, and quartz were sourced from Sigma-Aldrich. Quartz also acted as the procedural blank. Gypsum was acquired from $\mathrm{BDH}$ reagents and chemicals. Siderite was synthesized in the laboratory. Illite (IMt-1), kaolinite (KGa-1b), and montmorillonite (Swy-2) were obtained from The Clay Minerals Society. As these are pure singlephase standards, they are not directly Mars relevant, but studying their decomposition augments our analysis of the natural jarosite clay decomposition and our interpretation of the relative behavior of different sulfate species on Mars.

\section{2. $X$-ray diffraction $(X R D)$}

The natural jarosite clay was analyzed by XRD. A subset of the specimen was ground and homogenized in a pestle and mortar and mounted in a flat holder within a Panalytical X'Pert Pro Alpha-1 system. The powder was analyzed between 5 and $90^{\circ} 2 \Theta$ for three and a half hours under copper radiation with an $X^{\prime}$ Celerator detector. The diffraction pattern was analyzed with the X'Pert HighScore program with reference patterns from the ICDD PDF-2 database. The X'Pert software was used to perform a Rietveld refinement allowing quantification of crystalline phases in the sample to an accuracy of 1-3\%.

\subsection{Quantifying carbon in the natural jarosite clay}

To assess the quantity and nature of carbon in the natural jarosite clay, a $3 \mathrm{~g}$ sample was washed in $1 M$ hydrochloric acid. The acid was first pipetted dripwise onto the natural jarosite clay, but no effervescence was observed. So the sample was mixed with $10 \mathrm{~mL}$ of the acid. A centrifuge was used to separate the acid from the solid, and it was pipetted off and replaced with fresh acid $(\times 3)$. The natural jarosite clay was then rinsed in deionized water until the $\mathrm{pH}$ returned to 7. Samples of the untreated and acid-treated natural jarosite clay were analyzed by elemental analyzer-isotope ratio mass spectrometry (EA-IRMS) by Iso-Analytical Limited. EA-IRMS allows the total carbon in the sample to be measured. The difference in total carbon between the untreated and acid-treated samples allows the ratio of organic carbon to carbonate to be assessed.

\subsection{Solvent extraction}

To examine the extractable organic matter within the sample, $2 \mathrm{~g}$ of the natural jarosite clay was divided equally between two test tubes, and each sample was extracted with $5 \mathrm{~mL}$ of a 95:5 dichloromethane:methanol solvent mixture. 
The tubes were sonicated and then centrifuged, and the supernatant was pipetted off into a third test tube. The extraction was repeated three times, with the resulting supernatants added to the third test tube. The total supernatant was evaporated under nitrogen and then stored in a vial before subsequent analysis.

\subsection{Pyrolysis-gas chromatography-mass spectrometry (Py-GC-MS)}

Powdered samples were placed into quartz pyrolysis tubes and held in place by quartz wool. With all samples, other than siderite, $4 \mathrm{mg}$ of sample was used; the siderite experiment used only $3 \mathrm{mg}$, as the response of carbon dioxide is much greater for siderite relative to the other minerals. The pyrolysis tubes were placed inside the platinum coil of a CDS 5200 pyroprobe under helium and heated at a rate of $20^{\circ} \mathrm{C} \mathrm{ms}^{-1}$ to the target temperature, where it was held for $15 \mathrm{~s}$. The interface was held at $150^{\circ} \mathrm{C}$ and coupled to a gas chromatograph-mass spectrometer for direct injection. For the natural jarosite clay and ferric sulfate hydrate experiments, individual samples (i.e., samples run at one temperature step only, rather than using stepped pyrolysis) were run at $100^{\circ} \mathrm{C}$ intervals, the lowest at $400^{\circ} \mathrm{C}$ and the highest at $1000^{\circ} \mathrm{C}$, allowing both the products of pyrolysis and the variation in decomposition rate at different temperatures to be investigated. An additional individual analysis at $550^{\circ} \mathrm{C}$ was used to focus on decomposition around typical pyrolysis temperatures used for studying macromolecular organic material ( $\mathrm{Mu}$ and Perlmutter, 1981; Sephton and Gilmour, 2001; Sephton et al., 2004, 2013; Navarro-González et al., 2006; Sephton, 2012). For each of the other minerals being studied, two individual experiments were carried out, one at $600^{\circ} \mathrm{C}$ and one at $1000^{\circ} \mathrm{C}$ to show the decomposition characteristics at both typical pyrolysis temperatures and at the higher temperature to identify any species released under the full range of pyrolysis conditions. Additional individual natural jarosite clay samples were pyrolyzed at $600^{\circ} \mathrm{C}$ and $700^{\circ} \mathrm{C}$ with the gas chromatograph-mass spectrometer optimized for organic molecule detection (as described in the next section).

\subsection{Gas chromatography-mass spectrometry (GC-MS)}

The products of pyrolysis were analyzed by GC-MS with an Agilent Technologies 6890 gas chromatograph coupled to a 5973 mass spectrometer. The gas chromatograph injector was held at $200^{\circ} \mathrm{C}$ and operated in split mode (35:1) with a

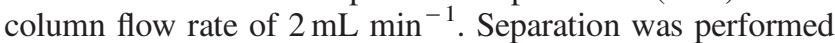
on a J\&W GS-Q PLOT column $(30 \mathrm{~m} \times 0.32 \mathrm{~mm})$. The gas chromatograph oven was held for $5 \mathrm{~min}$ at $35^{\circ} \mathrm{C}$ and then ramped at a rate of $10^{\circ} \mathrm{C} \mathrm{min}^{-1}$ to $200^{\circ} \mathrm{C}$, where it was held for 4 min. Mass spectra were acquired in the scan range 10$150 \mathrm{amu}$. In the natural jarosite clay and ferric sulfate hydrate experiments, the peak areas were normalized by sulfate mass in each run. We assumed $100 \%$ for the ferric sulfate hydrate standard and used the abundance of jarosite found by XRD for the natural jarosite clay.

To examine the products of natural jarosite clay pyrolysis for the presence of organic compounds, the gas chromatograph injector was held at $270^{\circ} \mathrm{C}$ and operated in split mode $(65: 1)$ with a column flow rate of $1.1 \mathrm{~mL} \mathrm{~min}^{-1}$. Separation was performed on a J\&W DB-5MS UI column $(28.9 \mathrm{~m} \times 0.25 \mathrm{~mm} \times 0.25 \mu \mathrm{m})$. The gas chromatograph oven was held for $2 \mathrm{~min}$ at $35^{\circ} \mathrm{C}$ and then ramped to $300^{\circ} \mathrm{C}$, where it was held for $8 \mathrm{~min}$. Mass spectra were acquired in the scan range 45-550 amu.

For the analysis of the solvent extract of the natural jarosite clay, an Agilent Technologies 7890A gas chromatograph coupled to a $5975 \mathrm{C}$ mass spectrometer was used. The gas chromatograph injector was held at $200^{\circ} \mathrm{C}$ and operated in splitless mode with a column flow rate of $1.1 \mathrm{~mL} \mathrm{~min}^{-1}$ and a solvent delay of four and a half minutes. Separation was performed on a J\&W DB-5MS UI column $(30 \mathrm{~m} \times 0.25 \mathrm{~mm} \times$ $0.25 \mu \mathrm{m})$. The gas chromatograph oven was held for $2 \mathrm{~min}$ at $40^{\circ} \mathrm{C}$ and then ramped to $310^{\circ} \mathrm{C}$ at a rate of $5^{\circ} \mathrm{C} \min ^{-1}$ to $310^{\circ} \mathrm{C}$, where it was held for $14 \mathrm{~min}$. Mass spectra were acquired in the scan range 40-550 amu.

\section{Results}

\subsection{Phases present in the natural jarosite clay sample}

Quantification by XRD showed that jarosite made up 5\% of the natural jarosite clay sample from Brownsea Island. Jarosite is concentrated on rock surfaces, with the bulk of the sample made up of quartz $(40 \%)$, goethite $(36 \%)$, and clay minerals (kaolinite, 10\%; illite, 9\%). XRD patternmatching indicates that the jarosite has a composition between the potassium and hydronium end-members.

\subsection{Carbon in the natural jarosite clay}

Both the untreated and acid-treated natural jarosite clay were found to have a carbon content of $0.45 \%$ by EA-IRMS, indicating that there is no significant carbonate component in the sample and that the carbon observed is organic carbon.

\subsection{Organic compounds present in the natural jarosite clay sample}

Solvent extraction indicated that the carbon in the natural jarosite clay contains extractable organic matter indicative of higher plant matter (undecane, heptadecane, octadecane, eicosane, methyl tetradecanoate, hexanol, hexadecanoic acid, octadecenoic acid, and octadecanoic acid). The natural jarosite clay was also contaminated by the plasticizer $N$ butyl-benzenesulfonamide.

\subsection{Decomposition products of ferric sulfates}

The major gases released by the natural jarosite clay at $600^{\circ} \mathrm{C}$ and $1000^{\circ} \mathrm{C}$ were carbon dioxide, water, and sulfur dioxide (Fig. 1). A minor peak of mass-to-charge ratio $(\mathrm{m} / \mathrm{z}$ ) 28 was also detected at both temperatures, which could be either nitrogen or carbon monoxide, as both species have the same mass and retention time. We infer that this species is more likely to be carbon monoxide, as it is an expected product of partial combustion, the peak area increased with temperature, and no $\mathrm{m} / \mathrm{z} 28$ peak was seen in any other sample apart from siderite (Figs. 2 and 3). Oxygen was not detected at any temperature step for the natural jarosite clay.

The lack of carbonate phases in the XRD data for the natural jarosite clay, along with identical EA-IRMS total carbon values for the untreated and acid-treated samples, indicates that the carbon dioxide detected was due to the breakdown of organic matter and not carbonate decomposition. Pyrolysis data for untreated and acid-treated natural 
FIG. 1. Total ion current chromatograms of the gaseous products released during individual heating experiments of samples of a natural jarosite clay and a lab standard of ferric sulfate hydrate at $600^{\circ} \mathrm{C}$ and $1000^{\circ} \mathrm{C}$. The $\mathrm{m} / \mathrm{z} 28$ peak is labeled as CO?, as it could be either carbon monoxide or nitrogen; we infer carbon monoxide as discussed in the text. Very minor peaks for oxygen and carbon dioxide were present in the ferric sulfate hydrate experiment at $600^{\circ} \mathrm{C}$ but cannot be seen at the scale of the figure. All chromatograms are presented at the same scale.

FIG. 2. Total ion current chromatograms of the gaseous products during individual heating experiments of lab standards representing the non-sulfate mineralogy of the natural jarosite clay sample. All chromatograms are presented at the same scale.
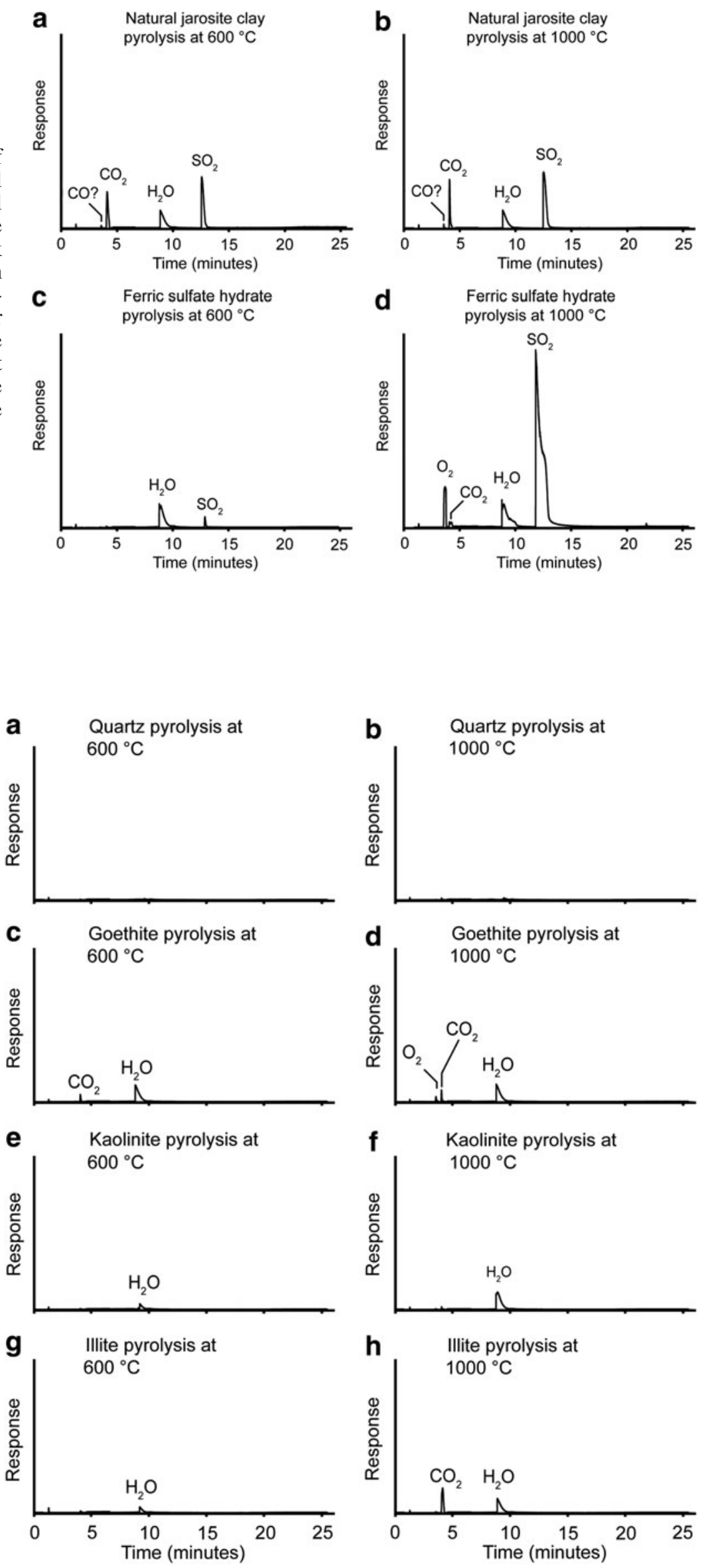

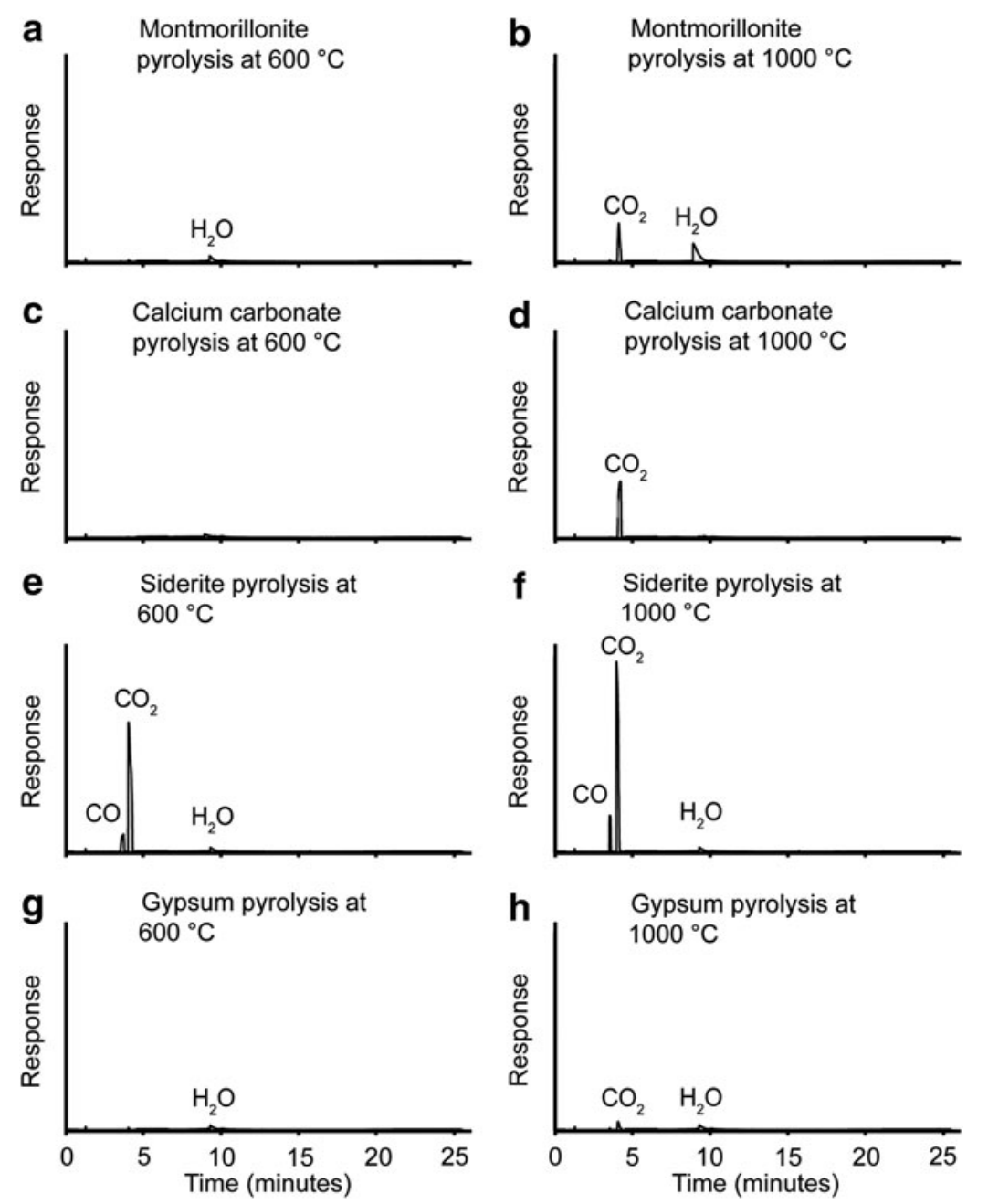

FIG. 3. Total ion current chromatograms of the gaseous products during individual heating experiments of lab standards representing other Mars-relevant minerals at $600^{\circ} \mathrm{C}$ and $1000^{\circ} \mathrm{C}$. All chromatograms are presented at the same scale. jarosite clay samples are almost identical, further indicating the absence of significant carbonate, because pyrolysis of a carbonate-containing sample would have generated much less carbon dioxide after being treated with acid. The substantial peak for sulfur dioxide indicates decomposition of the sulfate ions within jarosite and therefore decomposition to sulfur trioxide and then sulfur dioxide and oxygen (Bailey and Smith, 1972). However, as neither sulfur trioxide nor oxygen were detected directly, we infer that sulfur trioxide broke down rapidly and oxygen was completely consumed in the oxidation of organic matter. The oxidation of organic matter is therefore likely responsible for the majority of the carbon dioxide detected. Py-GC-MS of the natural jarosite clay, scanning in the range 45-550 amu with a DB-5MS UI column, found only that sulfur dioxide was detectable in the pyrolysis products, with a very minor benzene peak at $700^{\circ} \mathrm{C}$. None of the organic compounds detected through solvent extraction were detected through Py-GC-MS. At pyrolysis temperatures, these compounds were converted to carbon dioxide. Our observations suggest that jarosite decomposition can act as an oxidizer of organic matter.

At $600^{\circ} \mathrm{C}$, the lab standard of ferric sulfate hydrate produced distinct peaks for water and sulfur dioxide and extremely minor peaks for carbon dioxide and oxygen (Fig. 1). The sulfur dioxide peak area was substantially greater at $1000^{\circ} \mathrm{C}$ and was accompanied by an oxygen peak. Carbon dioxide was present at low levels during both the $600^{\circ} \mathrm{C}$ and $1000^{\circ} \mathrm{C}$ temperature steps. Only in the $1000^{\circ} \mathrm{C}$ experiment was the response great enough to be clearly visible in the chromatogram (Fig. 1). The carbon dioxide data suggest the thermal decomposition of a mineral impurity or minor contamination by organic compounds in the lab standard. Decomposition of sulfate ions can produce detectable oxygen during Py-GC-MS. Sulfur trioxide was not detected, suggesting it breaks down rapidly to sulfur dioxide and oxygen at temperatures equal to or greater than $600^{\circ} \mathrm{C}$.

\subsection{Decomposition products of other mineral phases}

The clay minerals and goethite present in the natural jarosite clay could be responsible for a major proportion of the water evolved during heating (Fig. 2). For the goethite standard, oxygen was present at low levels during both the $600^{\circ} \mathrm{C}$ and $1000^{\circ} \mathrm{C}$ experiments. However, only at $1000^{\circ} \mathrm{C}$ was the response clearly visible at the scale of the chromatogram. To investigate whether goethite could have contributed significant oxygen during decomposition of the natural jarosite clay, pyrolysis of the goethite standard was repeated with individual experiments at $100^{\circ} \mathrm{C}$ increments between $600^{\circ} \mathrm{C}$ and $1000^{\circ} \mathrm{C}$. When plotted on the same axes as the natural jarosite clay data, oxygen released by the goethite standard plots as a flat line and can be ruled out as a 
significant contributor of oxygen in the natural jarosite clay heating experiment. A minor carbon dioxide peak was seen at both temperatures, which suggests the presence of minor organic contamination in the lab standard. A distinct carbon dioxide peak was seen at $1000^{\circ} \mathrm{C}$ for illite, but none was detected at $600^{\circ} \mathrm{C}$. The data suggest decomposition of a carbonate impurity, as organic matter would have suffered substantial decomposition at $600^{\circ} \mathrm{C}$. Quartz was inert at both temperatures, which indicates that the experimental procedure did not contaminate the samples. Overall, none of the minerals analyzed can be implicated in the natural jarosite clay low-temperature carbon dioxide peak, so combustion of organic matter remains the most likely source.

Variation in clay species does not appear to be an issue. Montmorillonite released water at both $600^{\circ} \mathrm{C}$ and $1000^{\circ} \mathrm{C}$, and carbon dioxide appeared during the $1000^{\circ} \mathrm{C}$ step (Fig. 3 ). The carbon dioxide was again likely due to a carbonate impurity; a source by organic matter contamination is unlikely because of a lack of carbon dioxide detection at $600^{\circ} \mathrm{C}$. Siderite decomposes at both $600^{\circ} \mathrm{C}$ and $1000^{\circ} \mathrm{C}$ to give carbon dioxide and a $m / z, 28$ peak. The $m / z, 28$ peak is interpreted as carbon monoxide rather than nitrogen due to the homogeneity of the sample and the decomposition products of siderite being well known (Gallagher and Warne, 1981). Although siderite is a potential source of carbon dioxide, the XRD and EA-IRMS analyses showed that carbonate was absent in the natural jarosite clay; thus siderite was not a plausible source of significant carbon dioxide in this sample. Gypsum was pyrolyzed, and as expected from previous work (West and Sutton, 1953) it only dehydrated, suggesting that this common sulfate is relatively stable at pyrolysis temperatures used for the detection of organic matter. In summary, our data from experiments studying the decomposition of other relevant mineral phases suggest that carbon dioxide released from the natural jarosite clay must primarily have originated from oxidation of organic matter by oxygen derived from jarosite decomposition.

\subsection{Decomposition of ferric sulfates between $400^{\circ} \mathrm{C}$ and $1000^{\circ} \mathrm{C}$}

With the sources of the pyrolysis products from the decomposition of relevant mineral phases assessed, we performed further work to examine the relative response of pyrolysis products for the ferric sulfates with temperature (Fig. 4). The peak areas were normalized to the abundance of sulfate in the sample (100\% for the ferric sulfate hydrate and $5 \%$ of sample mass for the natural jarosite clay).

The natural jarosite clay sample and synthetic ferric sulfate hydrate both began to decompose to produce sulfur dioxide at around the temperatures used for the flash pyrolysis of macromolecular organic matter $\left(500-600^{\circ} \mathrm{C}\right)$. Yet the peak area for sulfur dioxide produced from jarosite decomposition was much greater than that seen in ferric sulfate. Sulfur
FIG. 4. The production of sulfur dioxide, carbon dioxide, possible carbon monoxide, and oxygen during the thermal decomposition of samples of natural jarosite clay and a lab standard of ferric sulfate hydrate in individual heating experiments carried out between $400^{\circ} \mathrm{C}$ and $1000^{\circ} \mathrm{C}$ at $100^{\circ} \mathrm{C}$ increments. ${ }^{*}$ The peak areas were normalized by sulfate mass $(100 \%$ in ferric sulfate hydrate, $5 \%$ of sample mass in the natural jarosite clay-from XRD results). The $\mathrm{m} / \mathrm{z}$ 28 peak is labeled as $\mathrm{CO}$ ?, as it could be either carbon monoxide or nitrogen; we infer carbon monoxide as discussed in the text.
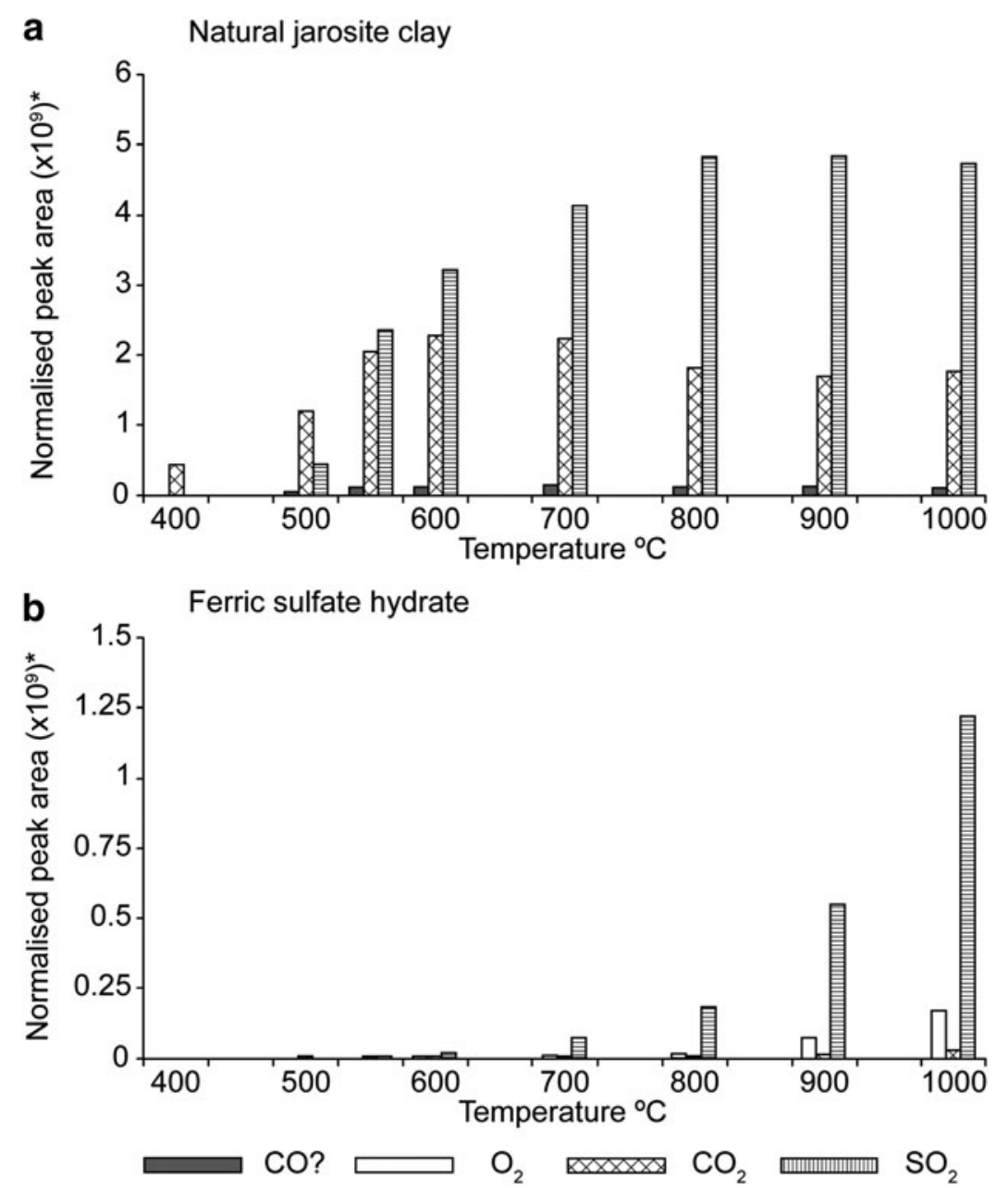
dioxide contributions from other minerals in the sample are implausible sources because XRD indicated that there are no other sulfates present in the natural jarosite clay.

Oxygen was not detected during heating of the natural jarosite clay but was detectable in the ferric sulfate hydrate experiments at temperatures at and above $600^{\circ} \mathrm{C}$ (Fig. 4). A substantial response for carbon dioxide appears at low temperatures for the natural jarosite clay from $500^{\circ} \mathrm{C}$, and a more limited response is evident at high temperatures from the ferric sulfate hydrate. The peak for the $\mathrm{m} / \mathrm{z} 28$ compound increases up to $550^{\circ} \mathrm{C}$, and its response is relatively constant thereafter in the natural jarosite clay. The rapid increase of carbon dioxide at temperatures normally associated with the decomposition of organic matter suggests that the combustion of organic matter was aided by sulfate-sourced oxygen. The peak areas for sulfur dioxide, water, and the $\mathrm{m} / \mathrm{z}, 28$ compound produced by the natural jarosite clay are very similar at $800^{\circ} \mathrm{C}$ and higher, indicating that the hydronium and ferric sulfate components in the potassium-hydronium jarosite were breaking down rapidly. The ferric sulfate hydrate peak areas were still increasing at $1000^{\circ} \mathrm{C}$, indicating that full decomposition had not yet been achieved. Oxygen increased with sulfur dioxide in the ferric sulfate hydrate experiments. Jarosite appears to break down rapidly at temperatures commonly used in thermal decomposition studies of organic matter.

To better understand the production of sulfur dioxide and carbon dioxide during pyrolysis of the natural jarosite clay, the peak areas were quantified with reference to calibration curves (Table 2). Sulfur dioxide was calibrated by manual injections of known volumes of gas and carbon dioxide through the pyrolysis of different masses of sodium bicarbonate. If the entire carbon content $(0.45 \%)$ of the natural jarosite clay was oxidized, then $1 \mathrm{mg}$ would be expected to produce $0.0165 \mathrm{mg}$ of carbon dioxide. The greatest mass of carbon dioxide produced per milligram of the natural jarosite clay was $0.0112 \mathrm{mg}$ at $600^{\circ} \mathrm{C}$, indicating that $68 \%$ of the carbon in the sample had been lost as carbon dioxide. Approximately a third of the organic carbon present must

Table 2. Carbon Dioxide, Sulfur Dioxide, and Theoretical OXYgen Production PER Milligram of Sample during Individual Pyrolysis Runs of the Natural Jarosite Clay

\begin{tabular}{lcccc}
\hline Memperature & $\begin{array}{c}\text { Mass } \\
\mathrm{SO}_{2} \\
(\mathrm{mg})\end{array}$ & $\begin{array}{c}\text { Theoretical mass } \\
\text { of } \mathrm{O}_{2} \text { release } \\
\text { during sulfate } \\
\left({ }^{\circ} \mathrm{C}\right)\end{array}$ & $\begin{array}{c}\text { Mass } \\
\mathrm{CO}_{2} \\
(\mathrm{mg})\end{array}$ & $\begin{array}{c}\mathrm{C}^{\mathrm{O}} \mathrm{O}_{2} \\
\text { molar }_{\text {ratio }}\end{array}$ \\
\hline 400 & 0 & 0 & 0.0021 & - \\
500 & 0.0020 & 0.0010 & 0.0057 & 4.2 \\
550 & 0.0104 & 0.0052 & 0.0099 & 1.4 \\
600 & 0.0155 & 0.0078 & 0.0112 & 1.0 \\
700 & 0.0190 & 0.0095 & 0.0110 & 0.8 \\
800 & 0.0224 & 0.0112 & 0.0089 & 0.6 \\
900 & 0.0228 & 0.0114 & 0.0085 & 0.5 \\
1000 & 0.0217 & 0.0109 & 0.0087 & 0.6 \\
\hline
\end{tabular}

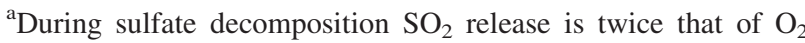
(Holt and Engelkemeir, 1970).

${ }^{b}$ Moles of carbon in $\mathrm{CO}_{2}$ detected divided by the moles of $\mathrm{O}_{2}$ released by sulfate decomposition. If the $\mathrm{C} / \mathrm{O}_{2}$ ratio is at or below one, then there is theoretically enough $\mathrm{O}_{2}$ produced by sulfate decomposition to generate all the $\mathrm{CO}_{2}$ by oxidation of organic matter. therefore be refractory and inaccessible by pyrolysis or combustion at temperatures $\leq 1000^{\circ} \mathrm{C}$.

All the oxygen in the carbon dioxide mass produced at $\sim 600^{\circ} \mathrm{C}$ and above could be oxygen sourced from sulfate decomposition (Table 2). The lower-temperature carbon dioxide that is not sourced from oxidation must still be sourced from the thermal processing of organic carbon, as carbonates are not present in the sample. The decarboxylation of carboxylic acids (which were detected in the solvent extract) are likely to be responsible (Alencar et al., 1983). Decarboxylation explains the mass of carbon dioxide detected at $400^{\circ} \mathrm{C}$ (Table 2 ), which appears before any sulfate decomposition occurs in the natural jarosite clay. Consequently, our data indicate that oxygen sourced from jarosite decomposition can oxidize a major proportion of indigenous organic carbon in a sample.

\section{Discussion}

\subsection{Effects of ferric sulfates on past, present, and future Mars missions}

It is evident from our data, therefore, that sulfate minerals represent a potential problem for the detection of organic matter on Mars by thermal extraction methods. Sulfates are abundant in martian rocks, regolith, and the well-mixed, globally spread dust. Here, it has been demonstrated that a well-mixed natural jarosite clay containing $5 \%$ jarosite can decompose at and above $500^{\circ} \mathrm{C}$ to release sulfur dioxide and, therefore, oxygen and in the process oxidize indigenous organic matter. Ferric sulfate hydrate also begins to decompose at similar temperatures to give sulfur dioxide. Gypsum and magnesium sulfate are unlikely to yield oxygen at the temperatures commonly employed for the thermal extraction of organic matter (Table 1). Much attention has been focused on the potential for perchlorate salts to disrupt thermal extraction experiments; it is the recommendation of the authors that ferric sulfates also be treated as a potential additional complication. Thermogravimetric studies suggest that aluminum sulfates may also disrupt organic detection experiments (Rudolph et al., 2003).

Our newly acquired sulfate data can be used to reexamine past experiments on Mars. Viking lander thermal volatilizationgas chromatography-mass spectrometry (TV-GC-MS) data have been reinterpreted to suggest that the decomposition of minerals, specifically perchlorates, may have precluded the detection of organic matter (Navarro-González et al., 2010). This reinterpretation was questioned by Biemann and Bada (2011), who stated that Viking data are not consistent with chlorination or oxidation of organic matter by perchlorates. Sulfates have not yet been directly considered as an additional confounding mineralogy during analysis on Mars. Inorganic chemical investigation on board the Viking Landers revealed high levels of sulfur (Clark et al., 1977). However, sulfur-containing compounds were absent in data from pyrolysis experiments at temperatures of $500^{\circ} \mathrm{C}$ and below (Biemann et al., 1977). Comparison of our data to those from the Viking experiments suggests that no potassium jarosite was present at the sample sites. Ferric sulfate may have been present, but pyrolysis temperatures would have been too low for substantial decomposition (Fig. 4). This comparison suggests that, even when confounding mineralogies exist, temperature windows can be identified within which pyrolysis studies can take place. 
Jarosite was inferred as a possible contributor to a water release detected between $295^{\circ} \mathrm{C}$ and $735^{\circ} \mathrm{C}$ by TEGA at the Phoenix landing site (Smith et al., 2009). However, no sulfur dioxide was detected in the heating range of 25$1000^{\circ} \mathrm{C}$ (Golden et al., 2009). Our data indicate that jarosite can therefore be removed from the list of potential dehydrating minerals suggested by Smith et al. (2009). Gypsum was interpreted as a possible phase in the Phoenix landing site soil (Hecht et al., 2009), an interpretation that is consistent with our data, which show that gypsum is unlikely to decompose to give sulfur dioxide below $1000^{\circ} \mathrm{C}$.

Recently, pyrolysis of surface materials from the Rocknest eolian deposit in Gale Crater led to the simultaneous release of oxygen and chlorinated hydrocarbons, suggesting the influence of perchlorates on organic decomposition (Glavin et al., 2013). Sulfur dioxide release was varied, suggesting heterogeneity in sulfur minerals, but a recognizable bimodal distribution existed with two peaks centered at $\sim 500^{\circ} \mathrm{C}$ to $550^{\circ} \mathrm{C}$ and $\sim 700^{\circ} \mathrm{C}$ to $750^{\circ} \mathrm{C}$ (Leshin et al., 2013). Notably, the lower-temperature release of sulfur dioxide was accompanied by an increase in carbon dioxide. As the lowertemperature carbon dioxide peak is significantly larger than sulfur dioxide, it is primarily consistent with the thermal decomposition of siderite (Leshin et al., 2013). However, it is possible that perchlorate decomposition-induced oxidation led to the degradation of organic matter at lower temperatures (ca. $350-450^{\circ} \mathrm{C}$ ), while jarosite decomposition-induced oxidation at slightly higher temperature $\left(\mathrm{ca} .450-550^{\circ} \mathrm{C}\right)$ exhausted any remaining organic matter, with the resulting carbon dioxide peak obscured by siderite decomposition (Leshin et al., 2013). However, the carbon dioxide and carbon monoxide produced by siderite decomposition could be misinterpreted as evidence of the combustion of organic matter, so interpretation of siderite-containing samples is extremely challenging. Multiple minerals may be complicating the search for indigenous organic matter on Mars. MSL pyrolysis of mudstone samples at Yellowknife Bay also produced chlorinated hydrocarbons and a sulfur dioxide peak centered at $600^{\circ} \mathrm{C}$. However, mudstones are indicative of neutral waters, rather than the low $\mathrm{pH}$ conditions needed for the formation of iron sulfates; thus sulfides are the more likely sulfur source at this locality (Ming et al., 2014). Though sulfates are widespread on Mars, the types of sulfur species found at each locality seem to be highly variable.

The negative influence of sulfate minerals on organic detection is magnified when it is noted that organic matter and sulfates have been observed to colocate in terrestrial Mars analog environments. Sulfates are an indicator of the presence of past liquid water, which is a prerequisite for the creation of habitable environments that can support life and its biochemistry. Glycine has been shown to associate with terrestrial jarosite samples and influence their decomposition (Kotler et al., 2009). It has been demonstrated that organic material can be preserved in ancient terrestrial sulfate minerals (Aubrey et al., 2006). Sulfate-rich Mars analog sites, such as Río Tinto and Panoche Valley, were found to have severely attenuated organic responses in thermal volatilization experiments by Navarro-González et al. (2006), but the decomposition of sulfate ions to give oxygen was not one of the confounding mechanisms considered by the authors. It appears that sulfates on Mars may represent something of a mixed blessing, acting as an effective host for organic matter but also reflecting a potentially aggressive material that is difficult to analyze.

The possible colocation of organic matter with sulfate minerals on Mars makes avoiding sulfates an unsatisfactory mitigation step, and other options must be considered. Only certain sulfates decompose to produce sulfur dioxide and then oxygen at the temperatures used for the detection of organic matter. A preliminary mineralogical analysis allows the risk of sulfate interference to be assessed. Such a method is used by MSL, where SAM results can be compared with data from the CheMin instrument (Glavin et al., 2013). If jarosite is detected, it would be a strong contender for the source of sulfur dioxide, water, and potentially oxygen and high-temperature carbon dioxide peaks (the latter being derived from the oxidation of organic matter) seen in thermal extraction experiments. In addition, the carbon dioxide peaks resulting from perchlorate and/or sulfate oxidation on Mars can be interpreted to indicate the masses of organic compounds being oxidized and potentially differentiate contamination from indigenous organic compounds (Sephton et al., 2014).

\section{Conclusions}

Sulfate minerals are commonly found on Mars. Iron sulfate species such as jarosite and ferric sulfate experience breakdown of their sulfate structures and therefore release oxygen around pyrolysis temperatures used to thermally extract organic matter. Sulfate decomposition can lead to the introduction of oxygen and/or sulfuric acid to pyrolysis chambers. Martian ferric sulfates therefore represent a significant complication to organic detection through heat-based methods. A large peak of carbon dioxide and a minor peak likely representing carbon monoxide were detected during pyrolysis of a natural jarosite clay sample, suggesting that the organic content is being combusted by oxygen released by jarosite decomposition. The prevalence of sulfates in martian rocks, regolith, and the globally mixed dust means that they are difficult to avoid. In addition, terrestrial sulfates have been shown to associate with organic compounds, so avoiding these minerals on Mars during organic detection experiments would be unwise. Previous authors have recognized that the decomposition of perchlorates on Mars may degrade organic matter. Sulfates may also be contributing to the oxidation of organic matter during thermal analyses, thereby complicating interpretations. However, the relatively high breakdown temperatures for sulfates mean that a combination of preliminary mineralogical analyses and suitably selected thermal extraction temperatures may minimize or remove their negative influence.

\section{Acknowledgments}

We sincerely thank Reuben Hawkwood, Nanette Cleary, and the rest of the National Trust staff at Brownsea Island, Dorset, for their permission and assistance in acquiring the natural jarosite clay sample. The authors are grateful for support from the Science and Technology Facilities Council, the UK Space Agency, and the Leverhulme Trust. Constructive reviews of the manuscript by four anonymous reviewers are gratefully acknowledged.

\section{Author Disclosure Statement}

No competing financial interests exist. 


\section{References}

Alencar, J.W., Alves, P.B., and Craveiro, A.A. (1983) Pyrolysis of tropical vegetable oils. J Agric Food Chem 31: 1268-1270.

Arvidson, R.E., Bell, J.F., Bellutta, P., Cabrol, N.A., Catalano, J.G., Cohen, J., Crumpler, L.S., Des Marais, D.J., Estlin, T.A., Farrand, W.H., Gellert, R., Grant, J.A., Greenberger, R.N., Guinness, E.A., Herkenhoff, K.E., Herman, J.A., Iagnemma, K.D., Johnson, J.R., Klingelhöfer, G., Li, R., Lichtenberg, K.A., Maxwell, S.A., Ming, D.W., Morris, R.V., Rice, M.S., Ruff, S.W., Shaw, A., Siebach, K.L., de Souza, P.A., Stroupe, A.W., Squyres, S.W., Sullivan, R.J., Talley, K.P., Townsend, J.A., Wang, A., Wright, J.R., and Yen, A.S. (2010) Spirit Mars Rover mission: overview and selected results from the northern Home Plate Winter Haven to the side of Scamander Crater. J Geophys Res 115, doi:10.1029/2010JE003633.

Atreya, S.K., Mahaffy, P.R., and Wong, A. (2007) Methane and related trace species on Mars: origin, loss, implications for life, and habitability. Planet Space Sci 55:358-369.

Aubrey, A., Cleaves, H.J., Chalmers, J.H., Skelley, A.M., Mathies, R.A., Grunthaner, F.J., Ehrenfreund, P., and Bada, J.L. (2006) Sulfate minerals and organic compounds on Mars. Geology 34:357-360.

Bailey, S.A. and Smith, J.W. (1972) Improved method for the preparation of sulfur dioxide from barium sulfate for isotope ratio studies. Anal Chem 44:1542-1543.

Baron, D. and Palmer, C.D. (1996) Solubility of jarosite at 4 $35^{\circ}$ C. Geochim Cosmochim Acta 60:185-195.

Basciano, L.C. and Peterson, R.C. (2008) Crystal chemistry of the natrojarosite-jarosite and natrojarosite-hydronium jarosite solid solution series: a synthetic study with full Fe site occupancy. Am Mineral 93:853-862.

Benner, S.A., Devine, K.G., Matveeva, L.N., and Powell, D.H. (2000) The missing organic molecules on Mars. Proc Natl Acad Sci USA 97:2425-2430.

Bibring, J.P., Langevin, Y., Mustard, J.F., Poulet, F., Arvidson, R., Gendrin, A., Gondet, B., Mangold, N., Pinet, P, Forget, F., and the OMEGA Team. (2006) Global mineralogical and aqueous Mars history derived from OMEGA/Mars Express data. Science 132:400-404.

Biemann, K. and Bada, J.L. (2011) Comment on "Reanalysis of the Viking results suggests perchlorate and organics at midlatitudes on Mars" by Rafael Navarro-González et al. J Geophys Res 116, doi:10.1029/2011JE003869.

Biemann, K., Oro, J., Toulmin, P., Orgel, L.E., Nier, A.O., Anderson, D.M., Simmonds, P.G., Flory, D., Diaz, A.V., Rushneck, D.R., Biller, J.E., and Lafleur, A.L. (1977) The search for organic substances and inorganic volatile compounds in the surface of Mars. J Geophys Res 82:4641-4658.

Bish, D.L., Blake, D.F., Vaniman, D.T., Chipera, S.J., Morris, R.V., Ming, D.W., Treiman, A.H., Sarrazin, P., Morrison, S.M., Downs, R.T., Achilles, C.N., Yen, A.S., Bristow, T.F., Crisp, J.A., Morookian, J.M., Farmer, J.D., Rampe, E.B., Stolper, E.M., Spanovich, N., and the MSL Science Team. (2013) X-ray diffraction results from Mars Science Laboratory: mineralogy of Rocknest at Gale Crater. Science 341, doi:10.1126/science.1238932.

Brophy, G.P. and Sheridan, M.F. (1965) Sulfate studies IV: the jarosite-natrojarosite-hydronium jarosite solid solution series. Am Mineral 50:1595-1607.

Burgess, R., Wright, I.P., and Pillinger, C.T. (1989) Distribution of sulphides and oxidised sulphur components in SNC meteorites. Earth Planet Sci Lett 93:314-320.
Catling, D.C., Claire, M.W., Zahnle, K.J., Quinn, R.C., Clark, B.C., Hecht, M.H., and Kounaves, S. (2010) Atmospheric origins of perchlorate on Mars and in the Atacama. J Geophys Res 115, doi:10.1029/2009JE003425.

Chevrier, V.F., Hanley, J., and Altheide, T.S. (2009) Stability of perchlorate hydrates and their liquid solutions at the Phoenix landing site, Mars. Geophys Res Lett 36, doi:10.1029/ 2009 GL037497.

Clark, B.C. and Van Hart, D.C. (1981) The salts of Mars. Icarus 45:370-378.

Clark, B.C., Baird, A.K., Rose, H.J., Toulmin, P., Christian, R.P., Kelliher, W.C., Castro, A.J., Rowe, C.D., Keil, K., and Huss, G.R. (1977) The Viking X ray fluorescence experiment: analytical methods and early results. J Geophys Res 82:4577-4594.

Devlin, D.J. and Herley, P.J. (1986) Thermal decomposition and dehydration of magnesium perchlorate hexahydrate. Geochimica et Thermochimica Acta 104:159-178.

Drouet, C. and Navrotsky, A. (2003) Synthesis, characterization, and thermochemistry of $\mathrm{K}-\mathrm{Na}-\mathrm{H}_{3} \mathrm{O}$ jarosites. Geochim Cosmochim Acta 67:2063-2076.

Ehlmann, B.L., Mustard, J.F., Swayze, G.A., Clark, R.N., Bishop, J.L., Poulet, F., Des Marais, D.J., Roach, L.H., Milliken, R.E., Wray, J.J., Barnouin-Jha, O., and Murchie, S.L. (2009) Identification of hydrated silicate minerals on Mars using MRO-CRISM: geologic context near Nili Fossae and implications for aqueous alteration. J Geophys Res 114, doi:10.1029/2009JE003339.

Elwood Madden, M.E., Bodnar, R.J., and Rimstidt, J.D. (2004) Jarosite as an indicator of water-limited chemical weathering on Mars. Nature 431:821-823.

Faure, P., Schlepp, L., Mansuy-Huault, L., Elie, M., Jarde, E., and Pelletier, M. (2006) Aromatization of organic matter induced by the presence of clays during flash pyrolysis-gas chromatography-mass spectrometry (PyGC-MS): a major analytical artifact. J Anal Appl Pyrolysis 75:1-10.

Frost, R.L., Weier, M.L., and Martens, W.N. (2005a) Thermal decomposition of jarosites of potassium, sodium and lead. $J$ Therm Anal Calorim 82:115-118.

Frost, R.L., Wills, R., Weier, M.L., and Martens, W.N. (2005b) Thermal decomposition of synthetic argentojarosite-implications for silver production in medieval times. Thermochim Acta 437:30-33.

Frost, R.L., Wills, R., Kloprogge, J.T., and Martens, W.N. (2006a) Thermal decomposition of hydronium jarosite $\left(\mathrm{H}_{3} \mathrm{O}\right) \mathrm{Fe}_{3}\left(\mathrm{SO}_{4}\right)_{2}(\mathrm{OH})_{6}$. J Therm Anal Calorim 83:213-218.

Frost, R.L., Wills, R., Kloprogge, J.T., and Martens, W.N. (2006b) Thermal decomposition of ammonium jarosite $\left(\mathrm{NH}_{4}\right) \mathrm{Fe}_{3}\left(\mathrm{SO}_{4}\right)_{2}(\mathrm{OH})_{6}$. J Therm Anal Calorim 84:489-496.

Gallagher, P.K. and Warne, S.J. (1981) Thermomagnetometry and thermal decomposition of siderite. Thermochim Acta 43:253-267.

Gellert, R., Rieder, R., Anderson, R.C., Bruckner, J., Clark, B.C., Dreibus, G., Economou, T., Klingelhöfer, G., Lugmair, G.W., Ming, D.W., Squyres, S.W., d'Uston, C., Wanke, H., Yen, A., and Zipfel, J. (2004) Chemistry of rocks and soils in Gusev Crater from the alpha particle X-ray spectrometer. Science 305:829-832.

Glavin, D.P., Freissinet, C., Miller, K.E., Eigenbrode, J.L., Brunner, A.E., Buch, A., Sutter, B., Douglas Archer, P., Atreya, S.K., Brinckerhoff, W.B., Cabane, M., Coll, P., Conrad, P.G., Coscia, D., Dworkin, J.P., Franz, H.B., Grotzinger, J.P., Leshin, L.A., Martin, M.G., McKay, C., Ming, D.W., Navarro-González, R., Pavlov, A., Steele, A., Sum- 
mons, R.E., Szopa, C., Teinturier, S., and Mahaffy, P.R. (2013) Evidence for perchlorates and the origin of chlorinated hydrocarbons detected by SAM at the Rocknest aeolian deposit in Gale Crater. J Geophys Res Planets 118:1955-1973. Golden, D.C., Ming, D.W., Sutter, B., Clark, B.C., Morris, R.V., Boynton, W.V., Hecht, M.H., and Kounaves, S.P. (2009) Sulfur mineralogy at the Mars Phoenix landing site [abstract 2319]. In 40 th Lunar and Planetary Science Conference Abstracts, Lunar and Planetary Institute, Houston.

Gooding, J.L. (1992) Soil mineralogy and chemistry on Mars: Possible clues from salts and clays in SNC meteorites. Icarus 99:28-41.

Hecht, M.H., Kounaves, S.P., Quinn, R.C., West, S.J., Young, S.M.M., Ming, D.W., Catling, D.C, Clark, B.C., Boynton, W.V., Hoffman, J., DeFlores, L.P., Gospodinova, K., Kapit, J., and Smith, P.H. (2009) Detection of perchlorate and the soluble chemistry of martian soil at the Phoenix lander site. Science 325:64-67.

Holt, B.D. and Engelkemeir, A.G. (1970) Thermal decomposition of barium sulfate to sulfur dioxide for mass spectrometric analysis. Anal Chem 42:1451-1453.

Klingelhöfer, G., Morris, R.V., Bernhardt, B., Schroder, C., Rodionov, D.S., de Souza, P.A., Yen, A., Gellert, R., Evlanov, E.N., Zubkov, B., Foh, J., Bonnes, U., Kankeleit, E., Gutlich, P., Ming, D.W., Renz, F., Wdowiak, T., Squyres, S.W., and Arvidson, R.E. (2004) Jarosite and hematite at Meridiani Planum from Opportunity's Mossbauer spectrometer. Science 306:1740-1745.

Kotler, J.M., Hinman, N.W., Richardson, C.D., Conly, A.G., and Scott, J.R. (2009) Laboratory simulations of prebiotic molecule stability in the jarosite mineral group; end member evaluation of detection and decomposition behaviour related to Mars sample return. Planet Space Sci 57:1381-1388.

Kounaves, S.P., Hecht, M.H., Kapit, J., Gospodinova, K., DeFlores, L. Quinn, R.C., Boynton, W.V., Clark, B.C., Catling, D.C., Hredzak, P., Ming, D.W., Moore, Q., Shusterman, J., Stroble, S., West, S.J., and Young, S.M.M. (2010) Wet chemistry experiments on the 2007 Phoenix Mars Scout Lander mission: data analysis and results. J Geophys Res 115, doi:10.1029/2009JE003424.

Kounaves, S.P., Carrier, B.L., O’Neil, G.D., Stroble, S.T., and Claire, M.W. (2014a) Evidence of martian perchlorate, chlorate and nitrate in Mars meteorite EETA79001: implications for oxidants and organics. Icarus 229:206-213.

Kounaves, S.P., Chaniotakis, N.A., Chevrier, V.F., Carrier, B.L., Folds, K.E., Hansen, V.M., McElhoney, K.M., O'Neil, G.D., and Weber, A.W. (2014b) Identification of the perchlorate parent salts at the Phoenix Mars landing site and possible implications. Icarus 232:226-231.

Leshin, L.A., Mahaffy, P.R., Webster, C.R., Cabane, M., Coll, P., Conrad, P.G., Archer, P.D., Atreya, S.K., Brunner, A.E., Buch, A., Eigenbrode, J.L., Flesch, G.J., Franz, H.B., Freissinet, C., Glavin, D.P., McAdam, A.C., Miller, K.E., Ming, D.W., Morris, R.V., Navarro-González, R., Niles, P.B., Owen, T., Pepin, R.O., Squyres, S., Steele, A., Stern, J.C., Summons, R.E., Sumner, D.Y., Sutter, B., Szopa, C., Teinturier, S., Trainer, M.G., Wray, J.J., Grotzinger, J.P., and the MSL Science Team. (2013) Volatile, isotope, and organic analysis of martian fines with the Mars Curiosity Rover. Science 341, doi:10.1126/science.1238937.

Mahaffy, P. (2008) Exploration of the habitability of Mars: development of analytical protocols for measurement of organic carbon on the 2009 Mars Science Laboratory. Space Sci Rev 135:255-268.
Michalski, J.R., Cuadros, J., Niles, P.B., Parnell, J., Rogers, D., and Wright, S.P. (2013) Groundwater activity on Mars and implications for a deep biosphere. Nat Geosci 6:133-138.

Ming, D.W., Lauer, H.V., Archer, P.D., Sutter, B., Golden, D.C., Morris, R.V., Niles, P.B., and Boynton, W.V. (2009) Combustion of organic molecules by the thermal decomposition of perchlorate salts: implications for organics at the Mars Phoenix Scout landing site [abstract 2241]. In $40^{\text {th }}$ Lunar and Planetary Science Conference Abstracts, Lunar and Planetary Institute, Houston.

Ming, D.W., Archer, P.D., Glavin, D.P., Eigenbrode, J.L., Franz, H.B., Sutter, B., Brunner, A.E., Stern, J.C., Freissinet, C., McAdam, A.C., Mahaffy, P.R., Cabane, M., Coll, P., Campbell, J.L., Atreya, S.K., Niles, P.B., Bell, J.F., Bish, D.L., Brinckerhoff, W.B., Buch, A., Conrad, P.G., Des Marais, D.J., Ehlmann, B.L., Fairen, A.G., Farley, K., Flesch, G.J., Francois, P., Gellert, R., Grant, J.A., Grotzinger, J.P., Gupta, S., Herkenhoff, K.E., Hurowitz, J.A., Leshin, L.A., Lewis, K.W., McLennan, S.M., Miller, K.E., Moersch, J., Morris, R.V., Navarro-González, R., Pavlov, A.A., Perrett, G.M., Pradler, I., Squyres, S.W., Summons, R.E., Steele, A., Stolper, E.M., Sumner, D.Y., Szopa, C., Teinturier, S., Trainer, M.G., Treiman, A.H., Vaniman, D.T., Vasavada, A.R., Webster, C.R., Wray, J.J., Yingst, R.A., and the MSL Science Team. (2014) Volatile and organic compositions of sedimentary rocks in Yellowknife Bay, Gale Crater, Mars. Science 343, doi:10.1126/science.1245267.

Morris, R.V., Klingelhöfer, G., Schroder, C., Rodionov, D.S., Yen, A., Ming, D.W., de Souza, P.A., Wdowiak, T., Fleischer, I., Gellert, R., Bernhardt, B., Bonnes, U., Cohen, B.A., Evlanov, E.N., Foh, J., Gutlich, P., Kankeleit, E., McCoy, T., Mittlefehldt, D.W., Renz, F., Schmidt, M.E., Zubkov, B., Squyres, S.W., and Arvidson, R.E. (2006) Mössbauer mineralogy of rock, soil, and dust at Meridiani Planum, Mars: Opportunity's journey across sulfate-rich outcrop, basaltic sand and dust, and hematite lag deposits. J Geophys Res 111, doi:10.1029/2006JE002791.

Mu, J. and Perlmutter, D.D. (1981) Thermal decomposition of inorganic sulfates and their hydrates. Industrial \& Engineering Chemistry Process Design and Development 20:640-646.

Navarro-González, R., Navarro, K.F., de la Rosa, J., Iñiguez, E., Molina, P., Miranda, L.D., Morales, P., Cienfuegos, E., Coll, P., Raulin, F., Amils, R., and McKay, C. (2006) The limitations on organic detection in Mars-like soils by thermal volatilization-gas chromatography-MS and their implications for the Viking results. Proc Natl Acad Sci USA 103:16089-16094.

Navarro-González, R., Vargas, E., de la Rosa, J., Raga, A.C., and McKay, C.P. (2010) Reanalysis of the Viking results suggests perchlorate and organics at midlatitudes on Mars. $J$ Geophys Res Planets 115, doi:10.1029/2010JE003599

Rudolph, W.W., Mason, R., and Schmidt, P. (2003) Synthetic alunites of the potassium-oxonium solid solution series and some other members of the group: synthesis, thermal and X-ray characterization. European Journal of Mineralogy 15:913-924.

Saiz-Jiminez, C. (1994) Analytical pyrolysis of humic substances: pitfalls, limitations, and possible solutions. Environ Sci Technol 28:1773-1780.

Samadhi, T.W., Elliott, J.C., Jones, L.E., and Clare, A.G. (2001) Sodium sulfate decomposition in dry atmospheres. Glass Science and Technology 74:47-56.

Sephton, M.A. (2012) Pyrolysis and mass spectrometry studies of meteoritic organic matter. Mass Spectrom Rev 31:560-569. 
Sephton, M.A. and Gilmour, I. (2001) Pyrolysis-gas chromatography-isotope ratio mass spectrometry of macromolecular material in meteorites. Planet Space Sci 49:465-471.

Sephton, M.A., Wright, I.P., Gilmour, I., de Leeuw, J.W., Grady, M.M., and Pillinger, C.T. (2002) High molecular weight organic matter in martian meteorites. Planet Space Sci 50:711-716.

Sephton, M.A., Bland, P.A., Pillinger, C.T., and Gilmour, I. (2004) The preservation state of organic matter in meteorites from Antarctica. Meteorit Planet Sci 39:747-754.

Sephton, M.A., Court, R.W., Lewis, J.M.T., Wright, M.C., and Gordon, P.R. (2013) Selecting samples for Mars sample return: triage by pyrolysis-FTIR. Planet Space Sci 78:45-51.

Sephton, M.A., Lewis, J.M.T., Watson, J.S., Montgomery, W., and Garnier, C. (2014) Perchlorate-induced combustion of organic matter with variable molecular weights: implications for Mars missions. Geophys Res Lett 41, doi:10.1002/2014 GL062109.

Shimokawabe, M., Furuichi, R., and Ishii, T. (1977) Effects of metal oxide additives on the thermal decomposition of perchlorates, oxalates and hydroxides. Geochimica et Thermochimica Acta 20:347-361.

Smith, P.H., Tamppari, L.K., Arvidson, R.E., Bass, D., Blaney, D., Boynton, W.V., Carswell, A., Catling, D.C., Clark, B.C., Duck, T., DeJong, E., Fisher, D., Goetz, W., Gunnlaugsson, H.P., Hecht, M.H., Hipkin, V., Hoffman, J., Hviid, S.F., Keller, H.U., Kounaves, S.P., Lange, C.F., Lemmon, M.T., Madsen, M.B., Markiewicz, W.J., Marshall, J., McKay, C.P., Mellon, M.T., Ming, D.W., Morris, R.V., Pike, W.T., Renno, N., Staufer, U., Stoker, C., Taylor, P., Whiteway, J.A., and Zent, A.P. (2009) $\mathrm{H}_{2} \mathrm{O}$ at the Phoenix landing site. Science 325:58-61.

Steele, A., McCubbin, F.M., Fries, M., Kater, L., Boctor, N.Z., Fogel, M.L., Conrad, P.G., Glamoclija, M., Spencer, M., Morrow, A.L., Hammond, M.R., Zare, R.N., Vicenzi, E.P., Siljestrom, S., Bowden, R., Herd, C.D.K., Mysen, B.O., Shirey, S.B., Amundsen, H.E.F., Treiman, A.H., Bullock, E.S., and Jull, A.J.T. (2012) A reduced organic carbon component in martian basalts. Science 337:212-215.

ten Kate, I.L., Garry, J.R.C., Peeters, Z., Quinn, R., Foing, B., and Ehrenfreund, P. (2005) Amino acid photostability on the martian surface. Meteorit Planet Sci 40:1185-1193.

Vaniman, D.T., Bish, D.L., Chipera, S.J., Fialips, C.I., Carey, J.W., and Feldman, W.C. (2004) Magnesium sulphate salts and the history of water on Mars. Nature 431:663-665.

Vaniman, D.T., Bish, D.L., Ming, D.W., Bristow, T.F., Morris, R.V., Blake, D.F., Chipera, S.J., Morrison, S.M., Treiman, A.H., Rampe, E.B., Rice, M., Achilles, C.N., Grotzinger, J.P., McLennan, S.M., Williams, J., Bell, J.F., III, Newsom, H.E.,
Downs, R.T., Maurice, S., Sarrazin, P., Yen, A.S., Morookian, J.M., Farmer, J.D., Stack, K., Milliken, R.E., Ehlmann, B.L., Sumner, D.Y., Berger, G., Crisp, J.A., Hurowitz, J.A., Anderson, R., Des Marais, D.J., Stolper, E.M., Edgett, K.S., Gupta, S., Spanovich, N., and the MSL Science Team. (2014) Mineralogy of a mudstone at Yellowknife Bay, Gale Crater, Mars. Science 343, doi:10.1126/science.1243480.

Wanke, H., Bruckner, J., Dreibus, G., Rieder, R., and Ryabchikov, I. (2001) Chemical composition of rocks and soils at the Pathfinder site. Space Sci Rev 96:317-330.

West, R.R. and Sutton, W.J. (1953) Thermography of gypsum. J Am Ceram Soc 37:221-224.

Wong, A., Atreya, S.K., and Encrenaz, T. (2003) Chemical markers of possible hot spots on Mars. J Geophys Res 108, doi:10.1029/2002JE002003.

Zolotov, M.Y. and Shock, E.L. (2005) Formation of jarositebearing deposits through aqueous oxidation of pyrite at Meridiani Planum, Mars. Geophys Res Lett 32, doi:10.1029/ 2005 GL024253.

Address correspondence to: James Lewis

Earth Science \& Engineering South Kensington Campus Imperial College London $S W 72 A Z$

$U K$

E-mail: james.lewis07@imperial.ac.uk

Submitted 20 February 2014 Accepted 27 December 2014

$\begin{aligned} & \text { Abbreviations Used } \\ & \text { CheMin }= \text { Chemistry and Mineralogy } \\ & \text { EA-IRMS }= \text { elemental analyzer-isotope ratio mass } \\ & \text { spectrometry } \\ & \text { GC-MS }=\text { gas chromatography-mass spectrometry } \\ & \text { MSL }=\text { Mars Science Laboratory } \\ & m / z=\text { mass-to-charge ratio } \\ & \text { Py-GC-MS }=\text { pyrolysis-gas chromatography-mass } \\ & \text { spectrometry } \\ & \text { SAM }=\text { Sample Analysis at Mars } \\ & \text { TEGA }=\text { Thermal Evolved Gas Analyzer } \\ & \text { XRD }=\text { X-ray diffraction }\end{aligned}$

